\title{
Signification, innovation and stereotypes
}

\section{RESUMO}

Este texto examina o papel dos estereótipos na significação, especialmente em termos da semiótica de Peirce e suas conseqüências para a prática do design. Ele enfetiza a presença escondida de pressupostos do senso-comum na inferência, o processo lógico que Peirce via como a maneira falível, provisional e retórica através da qual os sujeitos produzem sentido. Contudo, se espera que o efeito relativista desestabilizador da semiose possa também ser capaz de produzir mudanças desejadas nas idéias recebidas quando a negatividade (ou rejeição) é ativada pelas práticas materiais do design (publicidade, arquitetura, fotografia, etc.) sempre que se quer criar proposições inovadoras, concretas, com o objetivo de alterar espectros específicos de preposições existentes.

\section{PALAVRAS-CHAVE}

- estereótipos

- inovação

- significação

\section{ABSTRACT}

This text examines the role of stereotypes in signification, especially in terms of Peirce's semiotics, and its consequences for design practice. It stresses the hidden presence of commonsensical assumptions in inference, the logical process which Peirce saw as the fallible, provisional, rhetorical way through which subjects produce sense. However, the relativistic and destabilizing effect of semiosis is also expected to be able to produce desirable changes in received ideas when negativity (or rejection) is activated by material practices of design (advertising, architecture, photography, etc) whenever one wishes to create concrete, innovative propositions, with the objective of altering specific aspects of existing solutions.

\section{KEY WORDS}

- innovation

- signification

- stereotypes

\section{Flávio Vinicius Cauduro FAMECOS/PUCRS}

$P$ eirce's semiotics constantly stresses the diagrammatic nature of thoughts. He says that all reasoning whatsoever is effected through constructions which generally take the form of diagrams, or visual arrays of characters and lines: 'That the process of forming a habit of reasoning by the use of diagrams is often performed there is no room for doubt' (Peirce 1940/1955: 123, 138). He saw those mental, imaginary diagrams as being icons of the same nature of syllogisms, the classical method for producing inferences.

Deductive inferences start from universal, valid premises to arrive at specific formal conclusions. Conversely, we can also start from results of experiments and observations, trying to arrive at possible general rules or laws (in induction) or causes (in hypothesis) which may reasonably explain the observed phenomena. Such provisional truths can be used later on by people's deductive reasoning.

Contrary to Saussure's semiology, who regarded words as the smallest units of signification and treated signifieds as if they were forever bonded with their signifiers, thus making of signification a mechanistic, linear process working through the enchainment of atomistic elements or units (wordsigns) in line-utterances, Peirce saw signification as a subjective, logical (relational), probabilistic (for being fallible) process of articulating sign-associations (propositions) in a certain order, which produced certain meaning-effects for the predicating subject him/herself as well as for others.

Peirce saw in inferential practices a clear demonstration of how one might articulate thoughts trough semiosis or signification. For inference he saw comprehending not only one but three possible modes of thinking: deduction (the traditional rational mode of thinking of classical logic), induction (or generalization), and abduction (or causality).

Saussure, on the other hand, saw subjects only predicating deductively, for they were supposed to predicate the signified of a signifier in a consistent, denotational, and consensual way (according the doxa or the dictionary). For the distinctive feature of categorical, deductive logic, which informs Saussure's semiology, structuralism, and other theories based on formal schemes, is the axiomatic, nonprobabilistic, non-conditional nature of its judgments (or definitions).

For Peirce, thus, every human predication about reality was, consciously or not, supported by a logical, probabilistic triadic combination of sign-propositions (based on the classical syllogism used in logic). For instance, the statement 'Socrates is mortal' is a proposition which logicians say entails two other hidden propositions which support that judg- 
ment: 'All men are mortal' and 'Socrates is a man'. Peirce understood that we could analyze the meaning of any predication by reconstructing its probable original, supportive syllogism - a method which is still followed by modern logic, but with the difference that their practitioners purport not to care about the practical, 'existential import' as they say, consequences of their assumptions and 'conclusions' - as if logic could be 'just' another formal, neutral discipline, not grounded in material realities, nor productive of certain pragmatic, ideological effects on their readers/writers.

Copi (1986: 244), a logician, observes that whenever an argument is stated incompletely, part being 'understood' or 'only in the mind', it is called an enthymeme. Corbett (1965: 62), a rhetorician, agrees with that too - he says that the enthymeme has come to be regarded as an abbreviated syllogism, that is, an argumentative statement which contains a conclusion and one of the premises, the second premise being implied.

However, as Copi (1986: 5-14) notes, enthymemic propositions can be also put forward in one or more sentences: they appear in the form of commands, (rhetorical) questions, or noun phrases, which means that an argument or thought can be articulated in many ways, by means of a variable number of sentences, but which are always possible to convert to the classical triadic, syllogistic form prescribed by logic, for purposes of formal analysis.

But such an analytic translation cannot avoid changes in meaning of the original articulation at all. It seems, thus, that Peirce did not use syllogisms to obtain reductionistic translations of original texts, as logicians do, but as a semiotic object of analysis itself, for he was mainly concerned with the effects such traditional rational articulations produced on subjects.

Thus, one simple statement type subject-verb-object already constitutes an enthymeme, that is, a rhetorical proposition, because it provides the addressee or analyst with one proposition and two of the terms of a hypothetical complete argument or syllogism informing it. The other missing term has to be guessed or inferred from the context, in order to allow the analyst or reader to 'reconstitute' the other two propositions and their 'original' syntactical arrangement. A 'reconstitution' which is, in effect, a new 'constitution', for it is governed by many subjective assumptions of the reader. Thus, logical in practice is as rhetorical (or probable) and grounded on one's particular experience of reality as any other signifying practice. As Peirce hinted at, and as Derrida had systematically shown, since every reading produces the writing of new texts (and viceversa), there is no end to interpretation and no final certainty about the 'original' meaning or intention of any text.

'Proposition', by the way, is the name given by logicians to the 'meaning' intended by such incom- plete arguments, but it can also signify any one of the statements which make up the syllogistic argument (one of the premises or the conclusion).

Therefore, any predication (any subject-verb-object triadic relation, be it affirmative or negative, universal or particular) is said by Peirce to entail an imaginary syllogism. That is why Peirce sees intersubjective communication as always dependent upon subjective significations which, in turn, are ultimately dependent on beliefs created by thinking habits. Signification can never be based on a totally non-contradictory system of beliefs, for there is no such thing as 'the origin', 'the center' to support such a 'system', but simply many contradictory, heterogeneous, competing, and ever changing historic-subjective representations supporting them.

Many purely logical, formal modeling of communication assume that subjects share a great deal of habits, rules, laws, conventions and beliefs, and dismisses any conflict as being just a result of 'noise' or 'misunderstanding' in the 'line' or in the 'text'. Formalistic (declaredly a-rhetorical) models of communication repress the ambiguous, paradoxical, conflictual, chaotic and innovative aspects of signification - everything which is deemed 'illogical' or 'nonsensical' by their proponents, who tend to be idealists and reductionists afraid of anything which might produce 'disharmony' in communication (as if subjects did not, could not disagree with each other most of the time, when communicating, dialoguing with each other).

For that reason, their 'consensual' models and theories have to reinforce the old idea that the use by the subject of conventional wisdom, received ideas, traditional dogmas and beliefs, which constitute the so-called 'common-sense', is the 'secret' of good communication, while repressing, at the same time, dialogue, deviances, ruptures, invention and everything else which does not conform to (their) stereotypes.. Because they too are afraid of 'misinterpretations', that is, they do not want to promote communication as a pluralistic, dialogical, never ending practice of sharing beliefs and contrasting differences, without room for 'messages' being unproblematically sent or received.

Peirce, differently from structuralists, refused to view communication as a simple mechanical process of of coding/decoding 'messages', stressing instead the probabilistic and subjective nature of interpretation, on which any communicational (dialogical) practice is always dependent., According to him, communication depended on previous significations which was also an articulation of beliefs. For that reason, he was very suspicious of the value of commonsensical ideas in thinking:

'The truth is, that common-sense, or thought as it first emerges above the level of the narrowly practical, is deeply imbued with that bad logical 
quality to which the epithet metaphysical is commonly applied; and nothing can clear it up but a severe course of logic.' (Peirce 1940/1955: 9)

As we observe, Peirce's does not have much faith on the cognitive powers of ordinary common-sense. His pragmatist (probabilistic, logic-rhetorical) semiotic theory advocates instead that reasoning should be based on 'critical common-sensism', that is, the observation of the practical effects of one's beliefs upon one's behavior and immediate reality. That is, reasoning should be practiced as a critical dialogue too, that is, between one's beliefs and all pertinent sensorial data. He rejects simple intuitions, instinctive sensations or positivistic (and aprioristic) beliefs as a sound foundation for thinking. For the 'natural', the 'obvious', as well as the axiomatic or dogmatic 'truths' which inform common-sense, the doxa - they all aim at maintaining the status quo by inhibiting curiosity, invention, change and the predication of alternative, new 'truths'.

According to O'Sullivan, Hartley, Saunders and Fiske (1983: 222), stereotyping and stereotypes represent, in generic terms, sets of values, judgments and assumptions concerning the behavior, characteristics or history of particular groups as well as people in general, thus playing a central role in the organization of commonsensical discourses.

'We not only stereotype other people and things, but we stereotype ourselves', writes James Adams (1979: 21), a designer who theorizes upon creativity in design practice. Adams says that stereotypes are a serious handicap to perceive new combinations, new possibilities of meaning.

The opportunity to face new challenges, to define problems and then solve then in creative and innovative ways, thus finding new possibilities for signifying life and reality, is what one mostly enjoys in design practice. Design as problem-solving is mostly an innovative activity. But problem-solving is not exclusive to design and other practices of planning and devising, for all human beings are, in one way or another, involved with the overcoming of difficult situations through their daily actions. However, few people enjoy solving problems, perhaps because they fail to recognize that the stage of problem-solving should be always preceded by that of problem-positing. Most people tend to accept the problem as given, not realizing that problem-definition is part of the process too. As Adams (1979) observes,

'Few people like problems. Hence the natural tendency in problem-solving is to pick the first solution that comes to mind and run with it. The disadvantage of this approach is that you may run either off a cliff or into a worse problem than you started with. A better strategy in solving problems is to select the most attractive path from many ideas, or concepts.' (Adams 1979: xi)
Flexibility in defining problems and conceptualizing solutions, the pluralization of alternatives, the ability to put oneself in others' shoes, but also the willingness to engage in dialogue with other subjects of different age, sex, class, cultural and educational level, are attitudes which creative, socially and politically concerned designers cultivate and enjoy, in order to enrich their own and others' imaginations.

O'Sullivan and others (1983:40-41) also say that common sense is "knowledge whose "truth" is proposed as obvious, natural, inevitable, eternal, unarguable and "what we always/already know" ... [and which] is a site of social struggle'. Stereotyping, in its turn, they say is an 'extension of the fundamental, cognitive process of categorization, whereby we impose structure and make sense of events, objects and experience' (p.222-223).

Moreover, they say that 'stereotypes encourage an intuitive belief in their own underlying assumptions, and play a central role in organizing commonsense discourse'. As one can see, both stereotypes and common sense they sustain cannot help innovation or creativity and for that reason should be used only as 'conventional truths' to be rejected.

Now, as Barthes once said, stereotypes are a political fact, the principal fact of all ideologies. And the means by which stereotypes are fixed into our brains is by repetition, the most powerful and effective rhetorical operation there is, as advertisers, priests, educators and politicians, among others involved professionally with communications, know only too well. Coward \& Ellis, for instance, say that 'The point at which the process of denotation [naturalization] is expressed most clearly is in the repetition without variation of stereotypes, something that takes place throughout our culture' (Coward \& Ellis 1977: 54, my italics). However, the need for repetition can also and paradoxically be read positively, because it confirms the intrinsic instability of one's subjectivity. Ideologemes, or habits, or conventions, or symbols do not remain very long in one's preconscious thinking unless they are permanently enforced and reinforced through their repetition via representations of the media, and all other types of sociocultural practices of signification. We also know that the earlier in life one's exposure to an ideologeme is, the longer the effect it causes in one's behavior will be and the longer it will last there. The work of linguists with aphasics (chiefly Jakobson's - see Holenstein 1974/1976) has shown, for instance, that the first linguistic signs we have learned are the ones which are most difficult to lose; conversely, the most recently acquired signs are the easiest to forget. Propaganda and advertising, of course, are very well aware of the need and value of repetition for the retention of their representations, as well as design consultancies which specialize in corporate identity programs, public signage, packaging, and other serial representations, aimed at the fixation of 
basic symbolic themes in the public mind. Lenin, for instance, also saw in repetition the key operation supporting ideology, which he recognized only existing as 'false' consciousness in capitalist minds, since he wrote that:

'...man's practice, repeating itself a thousand million times, becomes consolidated in man's consciousness by figures of logic [propositions]. Precisely (and only) on account of this thousand-million-fold repetition, these figures have the stability of a prejudice, an axiomatic character'. (In Kristeva 1974/1984: 199-200).

Freud, in his turn, saw the compulsion to repeat as an effect of 'the essentially conservative character of instincts' (Freud 1910/1986: 241, my italics). And Peirce too posited that our thinking habits were the product of repetition, for, as he said it, 'all vital processes tend to become easier on repetition. Along whatever path a nervous discharge has once taken place, in that path a new discharge is more likely to take place' (Peirce 1940/1955: 128).

Peirce did not believe either that commonsensical wisdom could explain or promote changes. For the simple fact, one can assume, that for him whatever was 'a matter of common sense' was ipso facto redundant and obsolete (and probably derived, one could add, from old, long forgotten, assumptions whose aim was to reject change, in order to transcend their own historical time and particular sociocultural context).

'Critical common-sensism', as Peirce called it, was his philosophical basis to counteract naive notions. It was, in his view, a critical reasoning of commonsensical thoughts which occur to one's mind most of the time. Its aim was to mediate and interpret immediate consciousness (the work of Firstness and Secondness alone, or habitual sensations and denotations) through a logical method of inquiry (which he called Thirdness, a reasoned interpretation of one's own interpretative beliefs, a kind of endless internal dialogue). His aim was to observe, to criticize and to evaluate the practical implications or effects (for the predicating subject) of 'the ordinary axioms of reasoning and of morals, as well as ordinarily developed ideals, as soon as they are extended so as to become applicable to the new world created by science' (Peirce 1940/1955: 298).

As we notice, due to his scientific formation, Peirce was more interested in criticizing logical failures of common-sense in relation to its immobilistic stance, when explaining the changing world of science (an immobilism which worked against man's natural curiosity for new and better 'truths'), than criticizing its effects in relation to the wider sociocultural world.

The full potential and practical implications of his semiotic theories were not realized by Peirce himself, for he repressed their relativism and sophistical features, due to his humanistic beliefs in God, soul, individuality, self-control, etc. He was able to demonstrate the value of statistics, of probabilistic inference, in the explaining and predicting of scientific events and experiments and their results, but he forgot to account for the role of material, historical, sociocultural practices in the production, reproduction and change of one's beliefs.

He preferred to analyze and explain the natural, random evolution of the universe, and its effects upon subjects, instead of trying to analyze the interference and co-participation of historical subjects in the direction taken by all sorts of changes in one's sociocultural environment. For that reason, some additional comments about 'common-sense' have to be added to Peirce's own remarks.

As Weedon (1985) observes, the most usual guarantors of the 'truth' of cultural discourses are science, God and common sense. Therefore, stresses Weedon, 'Common sense and the liberal-humanist tradition upon which it is founded suggest that every individual possesses an unchanging essence of subjectivity' (Weedon 1987: 105).

Thus, age, gender, race, genealogy, nationality and other similar conventional, ideological categorizations, are, according to common sense, what truly determine and define the essential, unchangeable attributes of human beings.

Additionally, according to certain stereotypes and their commonsensical formations, those factors help in 'explaining' why certain people are forever condemned to be naturally 'primitive', 'inferior', 'lazy', 'weak', 'hysterical', 'rebellious', etc, while others are naturally destined to be the 'elite', the 'developed', the 'talented', the 'powerful', the 'cultured', the 'intelligent' ones.

In consequence of such essentialistic, humanistic, commonsensical notions, she says:

'Consciousness is thought to be a continuous stream rather than the fragmented and contradictory effect of a discursive battle for the subjectivity of the individual. The exclusiveness of the assumption of a particular form of subjectivity, which rules out its alternatives, together with the individual subject's misrecognition of herself as the true author of her thoughts, speech and writing, gives the articulation of subjectivity in language the temporary appearance of fixity. This sense of fixity seems to rule out change.' (Weedon 1987: 77, my italics)

As Weedon (1987) also notes, the experience of subjects is far from homogeneous, for what a thing or event 'means' to a subject depends on the range of referential discourses, available to him/her at any particular moment, in his/her sociocultural context, to support alternative interpretations of his/ her reality. Those referential discourses cannot be 
homogeneous, for they come from the family, from the school, from the media, from science, from religions, from political parties, from philosophy, etc. The plurality of [one's] experience requires that 'interest groups put a great deal of energy, time and money into promoting certain views of the world... [To maintain their power and hegemony, a plurality of] norms must be constantly reaffirmed as part of the large body of common-sense knowledge upon which individuals draw for their understanding' (Weedon 1977: 79).

Weedon (1987) emphasizes that commonsensical knowledge, based on unconscious 'ideologies' or 'habits', is not a monolithic, cohesive body of assumptions, for it derives from multiple and contradictory sources, and, for that reason, it is not always necessarily conservative in its implications: its political effects depend on the particular context in which it is articulated (Weedon 1987: 77). Common sense is mainly reproductive in its effects, but sometimes it can also be transformative.

For there is no such thing as one permanent 'structure or system of ideas' 'overdetermining' our ultimate thoughts and actions, as Marxists want one to believe, but rather many, contradictory, open networks in interdependence, in continuous interaction, in our minds, consciously or otherwise. The re-cognition and re-production, as well as the restructuration and re-articulation of such internalized, heterogeneous, and sometimes contradictory sign-formations are thus possible and necessary.

Even if one tries hard to be coherent and stay the same, upholding always the same acts and beliefs, one cannot stay unchangeable - for new, external, diverging representations of reality are always interfering with our habitual way of thinking. If the subject is in process, as Peirce and Kristeva posited, then feedback is necessarily present and interfering, changing, one's mental processes and representations too.

Thinking, thus, involves both the re-cognition and re-production of familiar patterns - stereotypes as well as their re-formulation and re-articulation into new re-presentations. For the context, the environment, which also includes the thinking and interfering social subject, is never exactly the same, it is always changing, due to historical, sociocultural, political and economic forces in interaction, forces which orient signifying practices and their texts.

Thus, the radically new can only be achieved through a critical, dialogical, active engagement of subjects. The purposeful progression towards anything radically new requires the subject, first of all, to question and to challenge, systematically, the basic premises he/she activates in constructing propositions and on the conditionings they embody. For it is necessary to go further, to negate one's actions as well, which is something more than simply opposing dominant arguments. Because opposition is just an a contrario way of affirming a rule, of accepting the terms of the game (small letters vs. capital letters, black vs. white, female vs. male, etc). Negativity, or rejection, as Kristeva calls it, means more than that: it is a negation of negation, it is the superseding of polarized positions, it is rejection of existing dichotomies, of oppressive 'familiar' boundaries and constraints. It means radical structural changes, the search for new positions and new processes of signification, plus one's active participation in the everyday practices of re-producing reality.

The radically new can only be explained by the rejection of existing divisions and the production of new, more pluralistic ones. Negation is necessary for predication, but the permanence of purely dichotomic static boundaries is not. As Stuart Hall (1982) puts it:

\begin{abstract}
'Opposing arguments are easy to mount. Changing the terms of an argument is exceedingly difficult, since the dominant definition of the problem acquires, by repetition, and by the weight and credibility of those who propose or subscribe it, the warrant of 'common sense'. Arguments which hold to this definition of the problem are accounted as following 'logically'. Arguments which seek to change the terms of reference are read as 'straying from the point'. So part of the struggle is over the way the problem is formulated: the terms of the debate, and the 'logic' it entails.' (Hall 1982: 81, my italics)
\end{abstract}

In other words, when one really wants, desires to change something, one should be fighting for something new and not simply struggle against something old. To simply oppose a particular viewpoint or situation can only help to maintain existing divisions and legitimize the positions, processes and terms according to which it has been traditionally defined. The domain of the excluded terms always already precedes any opposition and is waiting for reactive dissenters who have not, nor will have, elaborated an alternative proposal to the situation.

Simple opposition does not promote any innovative thinking nor produces any significant changes at all. The boundary, and the binaristic relation it helps to maintain, remain intact and are validated by its acts. Caught in binarisms, the most 'radical' thing that can happen to a subject is ambivalence or alternance in his/her opinions, arising from an impossible tentative of the subject to remain neutral, with one foot on each side of the divide (paradox), or with both feet on the line (ambiguity), as Wilden (1980) has pointed out.

We have been constantly led to believe, until recently, that it was impossible to transcend traditional binary alternatives. But, as Kristeva has argued, the problem is not binary opposition per se, but the fatalistic belief which informs many theories, and ideologies, all of them stating that subjects cannot, con- 
sciously or otherwise, force, break, reject, dissolve existing boundaries and then reconstruct new ones, in addition to the associated belief that one cannot, or should not, attempt to escape dichotomies, and pluralize signifying relations simultaneously.

Those imaginary, limiting, dualistic beliefs are hard to overcome, because subjects have been constantly told by the representational practices that they ought to have a recognizable, frozen identity, respecting prescribed limits, staying preferably inside those defined by the dominant groups as being their 'natural' sociocultural space ('Society' and 'Culture'), and constantly upholding received, 'traditional' beliefs, norms, rules and conventions. Those 'traditional' discourses purport an individualistic sociocultural homogeneity for their subjects which, of course, is simply not there.

But subjects keep on believing in 'consensus' and in reproducing stereotypes and commonsensical assumptions, since there are many producers and re-producers, institutionalized interpreters and mediators of one's existence (philosophers, politicians, legislators, educators, priests, the media, etc), very much interested in 'conserving' and preserving 'truths' of the status quo whenever they serve their interests. Besides, what could be easier, and more popular, than to reassure people that all goes well, that the status quo is fine, that God and progress exists, that science and technology will take care of all our problems, that we are the best nation of the world, etc, etc.

However, common-sense rules, axioms, beliefs, and dogmas are becoming increasingly short-lived, in our post-modern era. For excluded subjects are increasingly realizing, through their struggle and through their activism, that fixed identities and oppositions are man-made (literally) fabrications, which aim at controlling the complex and heterogeneous possibilities of signifying of subjects for the sake of protecting those in power.

As Anthony Wilden (1987) summarizes it, in the title of one of his books, the most widely preached belief propagated by groups in dominance, their golden rule, is that the rules are no game. A maxim that represents very accurately the pragmatic philosophy of all those in power which believe their function is to protect us from 'revolutionary ideas'. For them, society and culture are monolithically and statically structured, and therefore subjected to law and order and should not be changed. Any deviations, disturbances, contradictions, or conflicts which threaten their preferred, dominant patterns (which are generally said to derive from transcendental, eternal and wise universal 'laws' or historical, sacred traditions), are therefore necessarily and consequently viewed as the work of outside agitators (Wilden 1980: 348).

Thus, 'good' subjects can only be seen by the ruling subjects as being those 'individuals' who peacefully and obediently comply with, and reproduce, in practice, their oppressive, preferred imaginary structures, and who also passively consume their pre-fabricated signs. Only artists, inventors and other institutionalized deviants are allowed by dominant groups to be different, to dissent from the commonsense, in their 'geniality' or 'chronically sick' mental state or inconformity.

Signification, for such guardians of truth, becomes a dangerous process, and communication a disturbing practice of re-structuration, re-articulation, and re-design of the given, and which becomes acceptable only when their own survival is at risk. Then they call on planners and designers to reformulate economic policies, social services, the urban environment, the identity of their corporations, and the launching of new programs, of packages and products of all sorts. But after a new pattern is achieved, the new state becomes dogma again for them, as anyone who has worked in design practices (advertising, architecture, packaging, and so on) knows only too well.

No wonder, then, that the most difficult task for a designer, according to most experts, is to persuade a prospective client or institution to change a traditional design which is perceived by the general public, or by many critics or users, as inadequate. For there are many producers, specially those administrating family enterprises or in decision-making positions in the public sector, who are subjected to conservative, bureaucratic, commonsensical, 'traditional' notions about their sociocultural role: they seem to think that their main task is to preserve things as they are, that they are not involved or responsible for the promotion of badly needed social changes at all. And there are many pseudo producers of knowledge, or educators, who think the same way. They are producers which simply reproduced the inherited or the given, avoiding as much as possible to sponsor, to participate in, or to encourage the production of radical new changes.

Thus, it is from the point of view of articulation of signs, of de-signing, or signifying anew, that Peirce's semiotic model is very useful to our understanding of how signification can be, and is, designed by subjects, for themselves and other subjects as well. For what Peirce shows in his writings, from a poststructuralist, postmodern, pluralistic position, is, in effect, that signification is a rhetorical process and communication its practice, and that any signifying practice they constitute is dependent on more or less unstable subjective positions and changeable relations of predication. His semiotics, when carefully applied, shows one how discourses are articulated, how representations are rendered believable by and to subjects, and why one cannot stop them changing.

Peirce's examination of the inferential model of logic is very instructive for understanding signification, for it shows, very pragmatically why one should pay special attention to how arguments are constructed and 
mediated, according to the different selections, combinations, and punctuations of the terms deployed by the predicating subject in their discourses.

As one readily notices, Peirce shows, somehow unintentionally, that the meaning of any predication depends upon a subjective, tentative process of selection and combination of other sign associations, in order to one obtain a result which may be seen related to the original proposition in a 'coherent' way, that is, such as to make one believe he/she can obtain an integrated, 'closed', 'harmonious', selfsustaining signifying pattern to explain the meaning of any proposition. A meaning which is not objectively given or decoded from messages, but which is rather an effect promoted by a limited number of signifiers, present in an external text as well as in the historical mental context of the subject.

Peirce's semiotics can thus be regarded as a theory which shows basic strategic types of rhetorical relationships, or interpretants, that subjects employ in producing signification, that is, in designing believable verbal as well visual argumentative patterns, through propositions of identity, similarity, contiguity, opposition, and so on.

Such contextualized semiotic relationships transcend and deconstruct conventional boundaries in order to create new plural relations, mainly of similarity and contiguity, between signs. This means using a 'poetic' interpretant which is in effect an operation, a process accomplished through material practice and fuelled by imagination and desire. It is not a matter of simply trying to 'observe' or 'discover' new similarities between signs, but rather a practical matter of how to deconstruct usual semiotic framings, how to de-signate ourselves to other positions through signs.

Creative design does not simply observe and reproduce signs, but first de-constructs traditional barriers and then makes possible the establishment of new sign-relations. Design is a de-signing, a signmaking practice which should demolish social walls, by the exploration, adventuring and inventing of new signifying correlations, and which translates new possibilities of meaning into visible, tangible non-divisive propositions. For design is not simply a mental process, but fundamentally a very concrete, active material practice of presenting and representing new material propositions to society.

We tend to fall in love with the first idea that seems to solve our immediate problem, by the principle of the least effort, by commodity, by habit, without trying other alternatives, other readings. For most people are educated to simply consume, understand, memorize, and re-produce other's representations, while critical dialogue, innovation and change are usually discouraged and repressed.

Designing is a fundamental ingredient of any material production, a practical/intellectual activity, a praxis. When geared towards innovation and change, it relies mostly in the making of concrete hypotheses, which are translated into all sorts of representations, products, services, processes, and materials.

Designing is always already a concrete signifying practice, rather than a formal 'language', be it graphic, typographic, photographic, or what else. For positing design practice as being or having a 'language' amounts to seeing it as a purely deductive process of re-production, as a process of applying familiar, stereotyped rules, formulas, conventions, codes to daily problems of signification, 'using' pre-formed, predefined signs and formulas only. Structuralist theories which try to see immanent structures, common forms, conventional types, shared patterns in products of design, forget all about the innovative, material, creative, generative practice of design.

Most designers intuitively know and agree with that, but seldom bother to posit it explicitly, for one reason or another, in semiotically oriented terms. Thiel (1981) is one important exception to that trend, in my understanding, for he has tried to reflect theoretically upon design through its practice, and not a-aprioristically, not through formalistic, linguistic, or structuralist theories. He has posited that design cannot but be an iterative, trial-and-error process of hypothesis-making aiming at transforming a given social reality:

'But what is design? What is it we do when we design? To answer this, we may say first that generally design involves an act of purposeful planning, or the devising of courses of action aimed at changing existing situations into preferred ones. More specifically, design may be said to be a means of optimizing the use of limited resources of time and material in the realization of predetermined objectives, in circumstances where no satisfactory precedents exist. Since we are interested in the 'best' way of accomplishing this goal, we face the necessity of originating and evaluating alternatives, and then choosing among then. To facilitate such choices, we logically estimate the probable consequences of each alternative, in effect constructing a model of the situation and testing each possible course of action in it before any action is taken in the real world. Design is thus an alternative-evoking and decision-rationalizing activity, involving a series of operations and decisions in an iterative process.'

Design, viewed as a process of inventing and reinventing reality, is neither a doctrine, a body of aesthetical, functional or moral concepts, nor a frozen taxonomic, 'system' or 'language', but rather a contextualized, heterogeneous practice of solving sociocultural problems involving subjects, their desires, historical ideologemes and multiple strategies of signification. 
The propositions that result from the designer's way of thinking might or might not survive very long, depending on the results of subsequent tests (consumers testing, as well as clients, producers, and marketing appraisals, for instance). New inferential links are always present in design solutions, for design is always solving new problems. No matter how similar the new conditions might initially seem to be in relation to past ones, we are always going to face the unknown, sooner or later, in critical stages of the process. This will then lead us to the new, no matter how humble it might seem in the end. And even such humble new solution-components might provoke strong resistances from others. Even small innovations validated by 'logical' or 'technical' tests, are potentially risky and unavoidable design hazards in our practice. Namely if we, consciously or not, go 'against the grain' or stir deep emotions with them - that is, if we contradict or oppose long-established norms, or cherished personal preferences, or comfortable clichés, or vested interests, or strongly held public, religious, political beliefs, and so forth.

It is from the point of view of articulation of signs, of de-signing, or signifying anew, then, that Peirce's semiotic model is very useful to our understanding of how signification can be, and is, designed by subjects for themselves and other subjects as well. What Peirce shows us in his writings is, in effect, that signification is a rhetorical process of making propositions and communication the practice of making them shared by others, but that any signifying practice one activates is dependent on more or less unstable subjective positions and changeable relations of predication.

In synthesis, his semiotics, when carefully analyzed, show us how discourses are articulated, how representations are rendered believable by and to subjects, despite them being permanently subjected to change. a Famecos

\section{REFERÊNCIAS}

ADAMS, James L. Conceptual Blockbursting: A Guide to Better Ideas, 2nd edition, New York: W W Norton \& Co, 1980.

COPI, I. M. Introduction to Logic, seventh edition, New York: Macmillan, 1986.

CORBETT, E. P. J. Classical Rhetoric for the Modern Student, Oxford: Oxford University Press, 1965.

COWARD, Rosalind, and ELLIS, John. Language and Materialism: Developments in Semiology and the Theory of the Subject, London: Routledge \& Kegan Paul, 1977.

FREUD, Sigmund. The Essentials of Psychoanalysis, selected, introduced and commented by Anna Freud, translated from the German by James Strachey, London: Penguin Books, 1910/1986.

HALL, Stuart. 'The rediscovery of 'ideology': return of the repressed in media studies', in Culture, society and the media, edited by Michael Gurevitch, Tony Bennet, James Curran and Janet Woollacott, University Paperbacks, London: Methuen, 1982.

HOLENSTEIN, E. Roman Jakobson's Approach to Language - Phenomenological Structuralism, translated by Catherine Schelbert and Tarcisus Schelbert, Bloomington: Indiana University , 1974/1976. (First published in 1974 as Jakobson ou le structuralisme phénoménologique, Paris: Éditions Seghers)

KRISTEVA, Julia. Revolution in Poetic Language, translated by Margaret Waller with an introduction by Leon S Roudiez, New York: Columbia University, !974/1984. (First published in 1974 as La révolution du langage poétique, Paris: Éditions du Seuil)

O'SULLIVAN, Tim; HARTLEY, John; SAUNDERS, Danny and FISKE, John. Key Concepts in Communication, Studies in Communication, edited by John Fiske, London: Methuen, 1983.

PEIRCE, Charles Sanders. Philosophical Writings of Peirce, selected and edited with an introduction by Justus Buchler, New York: Dover (First published in 1940 as The Philosophy of Peirce: Selected Writings, ed. by Justus Buchler, London: Routledge \& Kegan Paul), 1940/1955.

THIEL, Philip. Visual Awareness and Design: An Introductory Program in Conceptual Awareness, Perceptual Sensitivity, and Basic Design Skills, Seattle: University of Washington Press, 1981.

WEEDON, Chris. Feminist Practice and Poststructuralist Theory, Oxford: Basil Blackwell, 1987.

WILDEN, Anthony System and Structure: Essays in Communication and Exchange, 2nd ed., Social Sciences Paperback, no.200, London: Tavistock Publications Ltd, 1980.

\footnotetext{
The Rules are no Game: The Strategy of Communication, London: Routledge \& Kegan Paul, 1987.
} 